\title{
INFORMAÇÕES CONTÁBIL-FINANCEIRAS E CUSTO DE CAPTAÇÃO EM MERCADOS DE BONDS *
}

\author{
Maurício Ribeiro do Valle \\ Professor Doutor do Departamento de Contabilidade e Atuária - FEA/USP - Ribeirão Preto \\ E-mail: marvalle@usp.br
}

RESUMO

O artigo discute a questão do conteúdo informacional de números contábil-financeiros e analisa a relação entre estas informações e o custo de captação das maiores empresas do setor Papel \& Celulose que obtiveram recursos nos mercados americano e internacional de bonds durante o período 1991-98. Os indicadores contábil-financeiros analisados mostraram que as empresas brasileiras não apresentaram um elevado desempenho como as empresas que captaram recursos com um baixo custo, mas, também, não apresentaram características semelhantes às empresas - americanas e canadenses com profundos problemas financeiros - que captaram a um alto custo nos mercados estudados.

Palavras-chave: custo de captação, Papel \& Celulose, bonds, indicadores contábil-financeiros.
ABSTRACT

The article concerns the information provided by accounting/financial variables and analyzes the relationship between this information and the cost of funding for the largest Pulp and Paper companies that raised capital in the U.S. and international bond markets in the period 199198. The analyzed accounting/financial variables showed that Brazilian companies neither performed as well as the companies that raised capital with a low cost, nor presented the same characteristics as the companies - American and Canadian companies with large financial problems - that raised capital with a high cost in the studied markets.

Key words: cost of capital, Pulp \& Paper, bonds, accounting/financial variables.

\footnotetext{
* $\mathrm{O}$ autor agradece à CAPES pelo financiamento às pesquisas que precederam este trabalho, ao apoio institucional da FIPECAFI do Departamento de Contabilidade/FEA/ USP e do Center of Global Education da St. John's University, ao Alexandre Assaf Neto e ao Rudinei Toneto Jr. pelos comentários. Este artigo foi cedido, por este periódico, para publicação na Revista do CRC-SP.

Recebido em 13.11.2001.
} 


\section{INTRODUÇÃO}

O objetivo do presente artigo é analisar uma possível relação entre o custo de captação de empresas nos mercados internacional e americano de bonds e o desempenho dessas empresas medido por indicadores contábil-financeiros. Para cumprir esses objetivos, o trabalho foi dividido em quatro partes. Na primeira parte, discute-se a questão do conteúdo das informações contábil-financeiras. Na segunda, apresenta-se uma breve comparação entre os custos de captação das empresas de Papel \& Celulose nos mercados referidos. Na terceira, são apresentados os resultados da análise contábil-financeira realizada para as empresas estudadas. $\mathrm{Na}$ quarta parte, explora-se a situação financeira de empresas que captaram recursos a taxas semelhantes àquelas pagas pelas empresas brasileiras. Finalmente, algumas conclusões são traçadas.

A pesquisa analisou as condições das captações e as informações contábil-financeiras das 100 maiores empresas (escolhidas pelo critério vendas em 1995) do setor Papel \& Celulose ${ }^{1}$. Da amostra inicial de 100 empresas procedentes de 24 países conseguiuse identificar ${ }^{2}$ captações nos mercados internacional e americano de bonds durante o período estudado - de 1991 a 1998 - para 42 empresas de 10 nacionalidades. Para o estudo e análises desenvolvidas, chegou-se ao final da pesquisa com 178 captações que totalizaram aproximadamente US\$30 bilhões. Das 178 emissões, foram obtidas informações suficientes para o cálculo do Prêmio Recebido para 177 emissões, enquanto o Prêmio Pago foi obtido para apenas 148 emissões. A amostra contou com quatro empresas brasileiras - Aracruz Celulose, Companhia Suzano de Papel e Celulose, Indústrias Klabin de Papel e Celulose e Votorantim Celulose e Papel - que fizeram 10 captações no período coberto.

As informações sobre as emissões e os seus ratings - emitidos pela Standard \& Poor's e pela Moody's - foram obtidas, principalmente, de
Bondware-Capital Data (janeiro de 1999) e, subsidiariamente, de Moody's Bond Record e de Standard \& Poor's Ratings Direct. As informações contábil-financeiras das empresas foram obtidas a partir de Disclosure Database e, no caso das empresas brasileiras, da Economática. Ainda subsidiando as informações contábil-financeiras das empresas, utilizaram-se as bases de dados SEC-EDGAR (Estados Unidos) e CSA-SEDAR (Canadá), MELHORES E MAIORES-FIPECAFI/Revista EXA$\mathrm{ME}$, os sites e relatórios financeiros das empresas.

\section{RELATÓRIOS CONTÁBEIS E CON- TEÚDO INFORMACIONAL}

Diversos estudos procuraram explicar o rendimento de bonds de empresas americanas a partir de informações financeiras e contábeis das próprias empresas (ver por exemplo Ederington, Yamitz \& Roberts, 1987; e Ziebart \& Reiter, 1992), enquanto outros procuraram explicar o rendimento de bonds de empresas de diversos países a partir de variáveis macroeconômicas dos próprios países (ver por exemplo Eichengreen \& Mody, 1998; e Kamin \& Kleist, 1999). No primeiro tipo de estudo, não há problemas quanto ao conjunto de práticas contábeis, pois trata-se de um único país. No segundo tipo de estudo, apesar da existência de diversos países, não se usaram variáveis contábeis nas análises. Infelizmente, não foram encontrados estudos que considerassem vários países e variáveis contábeis das suas empresas. Logo, a questão que permanece é, sem dúvida, como lidar com contabilidades elaboradas em diferentes contextos econômicos, políticos, sociais e legais.

Apesar de não ter sido encontrado estudo específico que cobrisse essa questão foram identificados alguns estudos com preocupação similar. Estes estudos, geralmente comparando a informação contábil de uma série de países com a dos Estados Unidos, procuraram analisar o conteúdo informacional do lucro contábil quando

\footnotetext{
${ }^{1}$ A fonte destas informações é a Pulp \& Paper International, revista profissional deste setor, de setembro de 1996.

${ }^{2}$ Emissões identificadas representam as emissões para as quais foram obtidas informações suficientes para calcular o Prêmio Recebido ou o Prêmio Pago. Define-se Prêmio Recebido como sendo o ágio (yield spread) entre o Rendimento até o Vencimento (YTM - yield to Marurity) de cada emissão e o rendimento de um título do Tesouro americano de igual prazo de vencimento (Maturity). A única diferença entre o Prêmio Pago e o Prêmio Recebido é que, para o cálculo do Prêmio Pago, as comissões (fees) pagas pela empresa emissora aos bancos que organizaram e executaram a operação foram descontadas do preço de emissão, permitindo identificar o que as empresas receberam em termos líquidos. Os prêmios são apresentados, ao longo deste trabalho, em termos de pontos-base. Cada 100 pontos-base equivalem a 1 ponto percentual.
} 
elaborado de acordo com os princípios contábeis do país da empresa (GAAP estrangeiros) e quando ajustado para seguir os princípios contábeis americanos (GAAP americanos).

No estudo em que examinaram a validade da hipótese segundo a qual os GAAP americanos são melhores do que GAAP estrangeiros como padrão de 'financial reporting' para empresas estrangeiras nos Estados Unidos, Chan \& Seow (1996:142) encontraram resultados similares aos obtidos por outros pesquisadores. Entre os estudos que mencionam, está Meek (1983), a partir do qual Chan \& Seow inferem que "os investidores americanos consideram que os lucros baseados nos GAAP estrangeiros são exatamente tão úteis quanto aqueles baseados nos GAAP americanos, e que o relatório $20 \mathrm{~K}^{3}$ pode não prover informação incremental para os investidores americanos" (Chan \& Seow, 1996:143).

Chan \& Seow analisaram esta questão através de regressões entre o retorno da ação e o lucro baseado nos GAAP americanos dividido pelo preço da ação do início do período, e fizeram o mesmo exercício utilizando os GAAP estrangeiros (Chan \& Seow, 1996:145). A obtenção de R²s maiores nas regressões que utilizaram os GAAP estrangeiros levou os autores a inferir que "o lucro baseado nos GAAP estrangeiros tem maior conteúdo informacional do que o lucro ajustado aos GAAP americanos" (Chan \& Seow, 1996:150). Apoiados em Baumol \& Malkiel (1993), Chan \& Seow afirmam que "a diversidade nos ambientes econômicos e de negócios entre diferentes países podem resultar em lucros baseados em GAAP estrangeiros não traduzíveis ('untranslatable')" (Chan \& Seow, 1996:141). Para Chan \& Seow, "se o ambiente de negócios em um país estrangeiro é bastante diferente daquele prevalecente nos Estados Unidos, alguns daqueles aspectos únicos do ambiente de negócios naquele país podem ser meIhor refletidos pelo lucro dos GAAP estrangeiros do que pelo lucro reconciliado para os GAAP americanos" (Chan \& Seow, 1996:152). Concluindo, Chan \& Seow afirmam que os seus "resultados parecem sugerir que os lucros baseados nos GAAP estrangeiros podem transmitir informação que pode ser perdida na reconciliação para os GAAP americanos" (Chan \& Seow, 1996:156).

Outro estudo que coloca em dúvida o benefício da "tradução" dos números contábeis de determinados GAAP para outros é o estudo de Choi \& Levich (1991). Em pesquisa realizada junto a investidores institucionais, emissores, "underwriters" e reguladores, Choi \& Levich encontraram que o 'restatement" não é suficiente para remover os problemas da diversidade contábil" e sugeriram que "ou (a) os algoritmos de 'restatement' ainda estão num estágio muito primário de desenvolvimento; ou (b) os algoritmos existentes não são aplicados efetivamente; ou (c) nenhum algoritmo é capaz de produzir um 'restatement' próprio e com significado". Segundo os autores, "se o 'restatement' fracassa em ser um efetivo mecanismo de 'coping' por causa de (a) ou (b), então mais esforço em 'restatement' pode resultar em benefício. Se a resposta correta é "c", então investidores podem estar certos em desenvolver suas habilidades em ler e interpretar demonstrativos financeiros estrangeiros em seus formatos originais" (Choi \& Levich, 1991:11).

Os resultados de Chan \& Seow, de acordo com os quais os lucros segundo GAAP estrangeiros de certos países são mais pontuais e relevantes em termos de valor da informação ("timely and valuerelevant') do que lucros baseados nos GAAP americanos (Chan \& Seow, 1996:155), foram, em certa medida, consistentes com os resultados de Alford et al. (1993). Também estudando a relação entre retorno de ação e lucro contábil, Alford et al. concluíram que "lucros contábeis preparados de acordo com os GAAP da Austrália, França, Holanda e Reino Unido são mais 'timely and value-relevant' do que lucros contábeis preparados de acordo com os GAAP americanos. Os resultados para Bélgica, Canadá, Hong Kong, Irlanda, Japão, Noruega, África do Sul e Suíça não foram conclusivos. Por outro lado, lucros contábeis da Dinamarca, Alemanha, Itália, Cingapura e Suécia são ou menos 'timely' ou menos 'value-relevant' do que lucros segundo os

\footnotetext{
3 O "Form 20K" antecedeu o "Form 20F", que é um dos relatórios exigidos pela SEC para empresas que emitem ADR. No "Form 20F, os lucros determinados segundo os GAAP estrangeiros devem ser reconciliados aos GAAP americanos e os efeitos materiais devido as diferenças em políticas contábeis devem ser destacadas" (Chan \& Seow, 1996:142).
} 
GAAP americanos" (Alford et al., 1993:196 e 213).

Esta revisão bibliográfica a respeito do valor informacional da informação contábil permite endereçar a seguinte questão: sendo um dos objetivos deste trabalho é analisar o custo de captação de empresas instaladas em diversos países a partir de variáveis contábil-financeiras, qual deve ser o demonstrativo contábil a ser utilizado nesta análise: i) o demonstrativo original da empresa segundo os GAAP do seu país; ii) o demonstrativo original da empresa segundo os GAAP do seu país realizados alguns ajustes como aqueles feitos por Rajan \& Zingales (1995); ou iii) os demonstrativos convertidos, pela própria empresa, aos GAAP americanos $\mathrm{e}$, conseqüentemente, reduzindo a amostra às empresas que fizeram tal transformação?

Não desprezando o mérito e encorajando estudos que optem pelas alternativas (ii) e (iii), este trabalho fez a opção por (i) pelos seguintes motivos: a) as empresas que captam recursos através do mercado de eurobonds, o principal mercado em estudo, não estão submetidas à legislação americana, ou seja, não são solicitadas a apresentar os demonstrativos contábeis segundo as regras da SEC. Geralmente, as empresas apresentam, como parte do prospecto de emissão, os demonstrativos contábeis segundo os GAAP de seus próprios países. Às vezes, as empresas apenas realizam a simples conversão dos números em moeda local para o dólar americano. Por isto, descarta-se a alternativa (iii); b) como parte do objetivo do trabalho é explicar o rendimento que o investidor exigiu a partir dos números contábil-financeiros, como a rentabilidade calculada a valor de livro, deve-se identificar o número analisado pelo investidor para decidir sobre o preço do seu investimento. Então, coloca-se a seguinte pergunta: qual foi o número utilizado pelo investidor? O número publicado pela empresa, ajustado ou não, segundo o próprio investidor. Como o investidor, por diversas razões, inclusive por anonimato fiscal, é a parte mais oculta deste mercado, não há como descobrir, inclusive com extensa pesquisa, quais são os ajustes realizados pelos diversos investidores de uma emissão qualquer. Assim, qualquer ajuste que fosse feito aos dados originais não garantiria, em qualquer hipótese, a obtenção do número utilizado pelo investidor médio. Por isto, descarta-se a alternativa (ii); e, por último, (c) a partir dos estudos que evidenciam que as informações contábeis segundo os GAAP dos próprios paísessede das empresas possuem valor informacional e resultados que mostram que o retorno de mercado (em grande parte determinado pelos investidores) se correlaciona com o lucro contábil segundo os GAAP originais, optou-se pela alternativa (i).

\section{AS CAPTAÇÕES E OS SEUS CUSTOS}

A análise das captações - nos mercados internacional e americano de bonds - realizadas pelas maiores empresas do setor Papel \& Celulose permitiu a identificação de dois grupos claros de emissões e emissores. A partir dos ratings atribuídos pelas agências de classificação de crédito, especificamente Moody's e Standard \& Poor's, foi possível separar as empresas e emissões com alta daquelas com baixa classificação de crédito. Neste trabalho, o grupo das empresas com baixa classificação de crédito - High Yield Grade - foi denominado grupo "alto custo", enquanto o grupo com alta classificação - Investment Grade - foi denominado grupo "baixo custo".

As análises efetuadas mostraram indubitavelmente o custo superior de captação das empresas brasileiras quando comparado ao custo das outras empresas do setor de Papel \& Celulose no período de 1991 a 1998. Deve-se enfatizar que o Prêmio Recebido médio das captações brasileiras foi de 399 pontos, enquanto o das canadenses, 260 pontos, e o das americanas, 167 pontos. Das 10 captações brasileiras, 5 pagaram próximo e 2 pagaram bem mais do que as empresas americanas e canadenses do grupo "alto custo" - associadas a problemas operacionais ou financeiros - pagaram em média. O Quadro 1, abaixo, apresenta informações sobre as captações canadenses, americanas e brasileiras. 
QUADRO 1

\section{CAPTAÇÕES CANADENSES, AMERICANAS E BRASILEIRAS}

\begin{tabular}{|c|c|c|c|c|c|c|c|}
\hline País/Grupo/Empresa & $\begin{array}{l}\text { Indicador/ } \\
\text { Ano }\end{array}$ & $\begin{array}{r}\text { Prêmio Pago } \\
\text { (Spread em } \\
\text { Ptos Bases- } \\
\text { Treasury } \\
\text { Bond) }\end{array}$ & $\begin{array}{r}\text { Vencim. } \\
\text { do } \\
\text { Principal } \\
\text { (em anos) }\end{array}$ & $\begin{array}{r}\text { Prêmio } \\
\text { Recebido } \\
\text { (Spread em } \\
\text { Ptos Bases- } \\
\text { Treasury Bond) }\end{array}$ & $\begin{array}{r}\text { Vencim. } \\
\text { do } \\
\text { Principal } \\
(\text { em anos) }\end{array}$ & $\begin{array}{r}\text { Montante } \\
\text { (em US\$ } \\
\text { milhões) }\end{array}$ & $\begin{array}{r}\text { Número } \\
\text { de } \\
\text { emissões }\end{array}$ \\
\hline \multirow{4}{*}{$\begin{array}{l}\text { CANADÁ } \\
\text { Total }\end{array}$} & Média & 320 & 11 & 260 & 11 & 242 & 1 \\
\hline & Máximo & 663 & 20 & 608 & 20 & 600 & 3 \\
\hline & Mínimo & 105 & 6 & 96 & 6 & 100 & 1 \\
\hline & Somatória & & & & & 2,900 & 16 \\
\hline \multirow{4}{*}{$\begin{array}{l}\text { CANADÁ } \\
\text { Empresas do grupo } \\
\text { "Baixo Custo" }\end{array}$} & Média & 171 & 14 & 173 & 13 & 243 & 1 \\
\hline & Máximo & 293 & 20 & 279 & 20 & 600 & 3 \\
\hline & Mínimo & 105 & 7 & 96 & 7 & 100 & 1 \\
\hline & Somatória & & & & & 1,700 & 10 \\
\hline \multirow{4}{*}{$\begin{array}{l}\text { CANADÁ } \\
\text { Empresas do grupo } \\
\text { "Alto Custo" }\end{array}$} & Média & 438 & 8 & 383 & 8 & 240 & 1 \\
\hline & Máximo & 663 & 10 & 608 & 10 & 500 & 2 \\
\hline & Mínimo & 223 & 6 & 192 & 6 & 150 & 1 \\
\hline & Somatória & & & & & 1,200 & 6 \\
\hline \multirow{4}{*}{$\begin{array}{l}\text { EUA } \\
\text { Total }\end{array}$} & Média & 170 & 18 & 167 & 17 & 324 & 2 \\
\hline & Máximo & 811 & 31 & 741 & 31 & 910 & 12 \\
\hline & Mínimo & 31 & 5 & 35 & 3 & 6 & 1 \\
\hline & Somatória & & & & & 22,061 & 128 \\
\hline \multirow{4}{*}{$\begin{array}{l}\text { EUA } \\
\text { Empresas do grupo } \\
\text { "Baixo Custo" }\end{array}$} & Média & 103 & 20 & 93 & 19 & 315 & 2 \\
\hline & Máximo & 218 & 31 & 206 & 31 & 896 & 12 \\
\hline & Mínimo & 31 & 5 & 35 & 3 & 6 & 1 \\
\hline & Somatória & & & & & 17,036 & 107 \\
\hline \multirow{4}{*}{$\begin{array}{l}\text { EUA } \\
\text { Empresas do grupo } \\
\text { "Alto Custo" }\end{array}$} & Média & 528 & 8 & 449 & 9 & 359 & 2 \\
\hline & Máximo & 811 & 10 & 741 & 20 & 910 & 2 \\
\hline & Mínimo & 338 & 5 & 297 & 5 & 100 & 1 \\
\hline & Somatória & & & & & 5,025 & 21 \\
\hline \multirow{4}{*}{$\begin{array}{l}\text { BRASIL } \\
\text { Total }\end{array}$} & Média & 437 & 6 & 399 & 6 & 133 & 1 \\
\hline & Máximo & 611 & 8 & 577 & 8 & 400 & 2 \\
\hline & Mínimo & 228 & 3 & 215 & 3 & 60 & 1 \\
\hline & Somatória & & & & & 1,198 & 10 \\
\hline Aracruz Celulose & 1993 & 416 & 5 & 391 & 5 & 80 & 1 \\
\hline Aracruz Celulose & 1994 & 460 & 3 & 426 & 3 & 120 & 1 \\
\hline Aracruz Celulose & 1995 & 271 & 8 & 256 & 8 & 150 & 1 \\
\hline Aracruz Celulose & 1997 & & & 284 & 5 & 120 & 1 \\
\hline Cia Suzano de P e C & 1993 & 537 & 8 & 516 & 8 & 80 & 1 \\
\hline Klabin Fab de P e C & 1993 & 733 & 3 & 687 & 3 & 60 & 1 \\
\hline Klabin Fab de P e C & 1993 & 489 & 8 & 468 & 8 & 59 & 1 \\
\hline Klabin Fab de P e C & 1994 & 467 & 8 & 446 & 8 & 60 & 1 \\
\hline Klabin Fab de P e C & 1996 & 507 & 4 & 476 & 4 & 70 & 1 \\
\hline Voto-Votorantim Over* & 1997 & 228 & 5 & 215 & 5 & 400 & 1 \\
\hline
\end{tabular}

* Brasil-Netherlands Antilles

Notas: 1) Em relação ao prazo de vencimento, quando a emissão possui um Put e o rendimento até o Put é maior que o rendimento até o vencimento, considerou-se o prazo do Put. Por outro lado, quando há um Call e o rendimento até o Call é menor que o rendimento até o vencimento, considerou-se o prazo de vencimento do Call; e 2) a captação da Klabin em 1994 possui uma cláusula contratual pela qual o pagamento de juros sobe de $12.125 \%$ para $12.75 \%$ após 28 .dez.1997. Considerando-se esta cláusula no cálculo, os prêmios pago e recebido sobem 32 pontos-base. FONTES: elaboração própria a partir de BondwareCapital Data, Moody's e Standard \& Poor's. 
Apesar de o período estudado se iniciar em 1991, as primeiras captações de empresas brasileiras da amostra ocorreram em 1993, ano que se mostra adequado para o exame proposto por diversos motivos. Em primeiro lugar, nesse ano, há várias captações - totais (23) e brasileiras (3). Das americanas e canadenses, há captações dos dois grupos utilizados na análise de captação por país, os grupos "alto custo" e "baixo custo". Em segundo lugar, foi o terceiro ano de presença brasileira neste mercado, desde o marco do seu retorno em agosto de 1991, com uma captação da Petrobrás. Em terceiro lugar, pode-se sugerir que, como o caso das brasileiras aqui estudadas, foi também a primeira captação da empresa chilena no período. Por último, por anteceder a crise mexicana de dezembro de 1994, foi um ano ainda propício para inserções de empresas de países sub-desenvolvidos no mercado financeiro internacional.

Em 1993, a Aracruz, que captou em melhores condições entre as brasileiras, ofereceu um prêmio $50 \%$ maior que o custo médio de captação do período, enquanto a Suzano pagou praticamente o dobro, e a Klabin mais do que o dobro do Prêmio Recebido médio do período (261 pontos). Naquele mesmo ano, a empresa chilena da amostra pagou menos da metade do que a Suzano e a Klabin pagaram.

Os anos seguintes também permitiram ilustrar as condições relativas de captação das empresas brasileiras. Em 1994, as captações brasileiras foram aquelas que mais pagaram no período. Comparando-as com a média do período (262 pontos) fortemente influenciada pelas empresas americanas do grupo alto custo - a Aracruz pagou aproximadamente 160 pontos acima, e a Klabin, 180 pontos. As empresas brasileiras, que captaram por 8 anos (Put em 3 anos), pagaram aproximadamente 3.5 vezes mais que a empresa da Nova Zelândia, que captou, em média, por 20 anos. Em 1995, a
Aracruz pagou o dobro do Prêmio Recebido médio do período (127 pontos) e mais do que o dobro do que pagou a empresa chilena da amostra. Em 1996, a Klabin pagou a maior taxa do período, o que representou mais de 2.5 vezes a média paga no período (178 pontos). Finalmente, em 1997, a Aracruz captou pagando o dobro do Prêmio Recebido médio do período (141 pontos) e praticamente três vezes o que pagou a Celulosa Arauco y Constitution do Chile. A Voto-Votorantim, apesar de captar em condições melhores, também pagou um preço mais elevado, cerca de duas vezes o que pagou a chilena.

\section{O DESEMPENHO CONTÁBIL- FINANCEIRO DAS EMPRESAS}

Nesse item, estarão sendo analisadas comparativamente as empresas brasileiras frente às meIhores empresas da amostra segundo uma série de indicadores contábil-financeiros. Os indicadores que estão sendo incluídos neste estudo são o retorno sobre o investimento (ROI), o índice de cobertura das despesas financeiras (FC/dFin) ${ }^{4}$, o custo da dívida ( $C D)$, o nível de endividamento (B/S), o tamanho das empresas representado pelas vendas (V), a classificação de risco da empresa segundo Minsky (1982) e um índice de risco do fluxo de caixa denominado $Z$, comentado adiante.

Nas tabelas apresentadas neste item, foram incluídas as 5 primeiras empresas segundo o principal indicador da tabela e as empresas brasileiras. As tabelas apresentam informações para três anos: 1993, 1995 e 1997. Nos anos 90, os preços de celulose e papéis iniciam o período em alta e caem continuamente até o ano de 1993, quando iniciam uma rápida recuperação e atingem o pico em 1995. Em 1996, os preços caem um pouco para patamares médios e se mantêm nestes patamares em 1997. Assim, escolhendo 1993, 1995 e 1997, está se analisando o desempenho das empresas em

${ }^{4}$ Para representar o FC - Fluxo de Caixa, utilizou-se o Lajir acrescido das depreciações, ou seja, o EBITDA. 
conjunturas de preços as mais variadas possíveis. Adicionalmente, o período 93 a 97 coincide com o período no qual ocorreram as captações das empresas brasileiras.

Na Tabela 1, as empresas foram classificadas segundo o Retorno sobre o Investimento (ROI), utilizando a alíquota de IR oficial (IRo) para o cálculo do benefício fiscal da dívida e o Patrimônio Líquido a valor patrimonial (VP). A tabela também apresenta o custo da dívida (CD), a relação entre capital de terceiros - que inclui apenas fontes terceiras com juros explícitos - e capital próprio (B/S). Nas duas colunas seguintes, o ROI está aberto em seus componentes giro e margem. $\mathrm{O}$ giro diz respeito à relação entre vendas líquidas (V) e investimento, (I) e a margem refere-se à relação entre lucro antes dos juros (Laj) e vendas líquidas (V). Nas duas últimas colunas da tabela estão o retorno sobre o patrimônio líquido (RSPL) e a classificação das empresas segundo este indicador.

Deve-se examinar prudentemente ou mesmo desclassificar a Fort Howard e a Gaylord, empresas que apresentaram altos índices de rentabilidade (ROI) fortemente influenciados por fatores que não significam uma boa performance, como a existência de PL negativos. A Fort Howard acumulou PL negativo desde 1992, enquanto a Gaylord apresentou-o em 1991, 1992 e 1994. Com exceção destas duas empresas, todas as empresas que aparecem entre as 5 primeiras classificadas pelo ROI são empresas que tiveram baixo custo de captação.

As empresas brasileiras apresentam um baixíssimo ROI (a valor de livro). Quando comparadas às demais empresas, a melhor posição de uma empresa brasileira é ocupada pela Votorantim, em 1997, quando, apesar de apresentar apenas $4.7 \%$ de ROI, aparece em vigésimo lugar. A pior posição relativa também é da Votorantim, em 1995, quando aparece em quadragésimo primeiro lugar. Em termos absolutos, o pior desempenho é o da Suzano em 1993, quando apresenta um ROI negativo. Considerando este indicador, temos um desempenho bastante medíocre das empresas, que poderia justificar parte do alto custo de captação que tiveram durante este período. Vale notar o baixo giro das empresas brasileiras, principalmente quando comparado ao giro das empresas americanas. As brasileiras não apresentaram giro maior que 0.5 , enquanto as americanas, na grande maioria, apresentaram giro acima de 1.0. Em relação à margem, merece destaque a altíssima margem da Aracruz, o que a deixaria em primeiro lugar em todos os períodos analisados segundo este critério. No entanto, o giro desta empresa dificilmente poderia ter sido menor, e isso comprometeu seriamente a sua rentabilidade.

A Tabela 1, além do ROI, também apresenta os outros elementos que montam o retorno dos acionistas da empresa (RSPL), ou seja, o custo da dívida (CD) e o nível de alavancagem da empresa (B/S). Com pouquíssimas exceções, todas as empresas que estiveram classificadas entre as primeiras pelo critério do ROI também apareceram bem classificadas pelo critério do RSPL, o que pode ser verificado na penúltima coluna da tabela. Esta coincidência mostra que, além do bom resultado dos seus ativos, estas empresas obtiveram bons resultados com a utilização de recursos de terceiros. Aqui, há o paradoxo que se poderia associar aos ciclos virtuosos, quando as diferentes variáveis interagem reciprocamente de forma positiva e mutuamente reforçadora. No presente caso, dever-se-ia perguntar se os investimentos são rentáveis porque houve (e há) disponibilidade de capital (barato) quando houve (e há) necessidade de investimento, ou se há disponibilidade de capital porque os investimentos são rentáveis. 


\section{TABELA 1}

\section{ANÁLISE DA RENTABILIDADE, PL A VALOR DE LIVRO - 1993, 1995 E 1997}

\begin{tabular}{|c|c|c|c|c|c|c|c|c|c|}
\hline Data & Empresa & Clas & $\begin{array}{r}\text { ROI } \\
\text { (IRo, VP) }\end{array}$ & $\begin{array}{r}\text { CD } \\
\text { (IRo) }\end{array}$ & $\begin{array}{l}B / S \\
\text { (VP) }\end{array}$ & $\begin{array}{l}V / I \\
\text { (VP) }\end{array}$ & $\begin{array}{r}\text { Laj / V } \\
\text { (IRo) }\end{array}$ & Clas & $\begin{array}{r}\text { RSPL } \\
(\text { IRo, VP) }\end{array}$ \\
\hline 12/31/93 EUA & FORT HOWARD CORP & 1 & $15.3 \%$ & $-10.9 \%$ & & 0.56 & $27.2 \%$ & & \\
\hline 12/31/93 EUA & KIMBERLY-CLARK CORP. & 2 & $15.2 \%$ & $-4.4 \%$ & 0.64 & 1.78 & $8.5 \%$ & 1 & $22.1 \%$ \\
\hline 12/31/93 EUA & SONOCO PRODUCTS COMPANY & 3 & $12.1 \%$ & $-4.5 \%$ & 0.62 & 1.78 & $6.8 \%$ & 2 & $16.7 \%$ \\
\hline 09/30/93 EUA & ROCK TENN CO & 4 & $10.3 \%$ & $-4.9 \%$ & 0.22 & 2.40 & $4.3 \%$ & 4 & $11.5 \%$ \\
\hline 12/31/93 Holanda & NV KONINKLIJKE KNP BT & 5 & $7.4 \%$ & $-15.0 \%$ & 1.22 & 2.58 & $2.9 \%$ & 27 & $-1.9 \%$ \\
\hline 12/31/93 Brasil & Aracruz & 24 & $3.9 \%$ & $-16.1 \%$ & 0.63 & 0.14 & $27.2 \%$ & 31 & $-3.8 \%$ \\
\hline 12/31/93 Brasil & PAPEL SIMAO (Votorantim C P) & 28 & $2.5 \%$ & $-11.5 \%$ & 0.28 & 0.38 & $6.5 \%$ & 24 & $-0.1 \%$ \\
\hline 12/31/93 Brasil & Klabin & 32 & $1.5 \%$ & $-9.8 \%$ & 0.55 & 0.39 & $3.8 \%$ & 29 & $-3.1 \%$ \\
\hline 12/31/93 Brasil & SuzanoN & 37 & $-0.4 \%$ & $-7.9 \%$ & 0.65 & 0.23 & $-1.5 \%$ & 32 & $-5.7 \%$ \\
\hline 12/31/95 EUA & KIMBERLY-CLARK CORP. & 1 & $29.8 \%$ & $-6.5 \%$ & 0.69 & 2.49 & $12.0 \%$ & 3 & $45.8 \%$ \\
\hline 09/30/95 EUA & GAYLORD CONTAINER CORP. & 2 & $25.7 \%$ & $-7.4 \%$ & & 1.41 & $18.2 \%$ & & \\
\hline 12/31/95 EUA & WILLAMETTE INDUSTRIES, INC & 3 & $21.1 \%$ & $-4.2 \%$ & 0.63 & 1.47 & $14.4 \%$ & 7 & $31.8 \%$ \\
\hline 12/31/95 Canada & ABITIBI PRICE (ABITIBI-CONSOL.) & 4 & $20.7 \%$ & $-7.7 \%$ & 0.63 & 1.84 & $11.3 \%$ & 9 & $29.0 \%$ \\
\hline 12/31/95 EUA & FORT HOWARD CORP & 5 & $19.2 \%$ & $-5.9 \%$ & & 1.42 & $13.5 \%$ & & \\
\hline 12/31/95 Brasil & Aracruz & 28 & $10.9 \%$ & $-2.8 \%$ & 0.65 & 0.22 & $48.6 \%$ & 25 & $16.1 \%$ \\
\hline 12/31/95 Brasil & Klabin & 35 & $7.8 \%$ & $-5.0 \%$ & 0.52 & 0.54 & $14.5 \%$ & 35 & $9.2 \%$ \\
\hline 12/31/95 Brasil & Suzano & 39 & $4.9 \%$ & $-3.7 \%$ & 0.53 & 0.28 & $17.2 \%$ & 38 & $5.5 \%$ \\
\hline 12/31/95 Brasil & Votorantim C P & 41 & $2.8 \%$ & $-6.8 \%$ & 0.21 & 0.47 & $6.0 \%$ & 39 & $2.0 \%$ \\
\hline 12/31/97 EUA & KIMBERLY-CLARK CORP. & 1 & $21.6 \%$ & $-4.1 \%$ & 0.53 & 1.82 & $11.9 \%$ & 2 & $30.9 \%$ \\
\hline 12/31/97 EUA & FORT JAMES CORPORATION & 2 & $15.4 \%$ & $-4.9 \%$ & 6.01 & 1.44 & $10.7 \%$ & 1 & $78.4 \%$ \\
\hline 12/31/97 EUA & SONOCO PRODUCTS COMPANY & 3 & $15.2 \%$ & $-4.1 \%$ & 0.95 & 1.65 & $9.2 \%$ & 3 & $25.9 \%$ \\
\hline 12/31/97 EUA & RAYONIER, INC. & 4 & $12.1 \%$ & $-4.0 \%$ & 0.66 & 1.03 & $11.8 \%$ & 5 & $17.5 \%$ \\
\hline 12/31/97 EUA & CHESAPEAKE CORPORATION & 5 & $9.9 \%$ & $-3.4 \%$ & 0.88 & 1.22 & $8.1 \%$ & 7 & $15.7 \%$ \\
\hline 12/31/97 Brasil & Votorantim C P & 20 & $4.7 \%$ & $-12.2 \%$ & 0.39 & 0.24 & $19.7 \%$ & 29 & $1.8 \%$ \\
\hline 12/31/97 Brasil & Suzano & 25 & $4.0 \%$ & $-7.8 \%$ & 0.77 & 0.35 & $11.7 \%$ & 30 & $1.1 \%$ \\
\hline 12/31/97 Brasil & Aracruz & 28 & $3.7 \%$ & $-8.2 \%$ & 0.60 & 0.13 & $27.6 \%$ & 31 & $1.0 \%$ \\
\hline 12/31/97 Brasil & Klabin & 35 & $2.0 \%$ & $-5.4 \%$ & 0.60 & 0.40 & $4.9 \%$ & 34 & $-0.1 \%$ \\
\hline
\end{tabular}

Nota: as tabelas completas, com notas explicativas detalhadas, podem ser encontradas em Valle (2000).

FONTES: Disclosure-Primark e Economática, principalmente. SEC-EDGAR (Estados Unidos), CSA-SEDAR (Canadá), FIPECAFIMelhores e Maiores e sites e relatórios financeiros das empresas, subsidiariamente.

A Tabela 2 analisa um índice de cobertura dos juros. A relação entre o fluxo de caixa e as despesas financeiras mostra quão seguro deve ser, para os credores, o recebimento dos juros do capital emprestado. Por outro lado, esta relação também mostra a folga que a empresa tem, sem depender do rendimento dos novos investimentos, para assumir novos encargos financeiros. A Tabela 2 mostra a relação entre o fluxo de caixa e as despesas financeiras (FC / dFin), o custo das dívidas (CD) e o nível de alavancagem, considerando valores histórico e de mercado para o patrimônio líquido.

Exceto no ano de 1995 - ano de altos preços da celulose e do papel, quando Aracruz e Votorantim $\mathrm{CP}$ se colocam entre as 10 primeiras - as empresas brasileiras apresentaram baixíssima relação entre fluxo de caixa e despesas financeiras, quando comparadas com as demais empresas. Eliminando estas duas empresas em 1995, as demais que aparecem entre as primeiras nesta tabela captaram recursos no mercado financeiro internacional pagando um baixo prêmio em relação aos títulos do Tesouro americano. As colunas 6 e 7 da tabela mostram que as empresas brasileiras estão entre as empresas que têm maior custo de dívidas, o que, em parte, ajuda a explicar o baixo índice de cobertura que possuem. Apesar de os índices de endividamento destas empresas serem apresentados nas últimas quatro colunas da Tabela 2, eles serão melhor analisados adiante. 
TABELA 2

ANÁLISE DO FLUXO DE CAIXA - 1993, 1995 E 1997

\begin{tabular}{|c|c|c|c|c|c|c|c|c|c|c|}
\hline Data & País & Empresa & Clas & $\begin{array}{l}\text { FC / } \\
\text { dFin }\end{array}$ & Clas & $\begin{array}{r}\text { CD } \\
\text { (IRo) }\end{array}$ & Clas & $\begin{array}{l}\text { B / S } \\
\text { (VM) }\end{array}$ & Clas & $\begin{array}{l}B / S \\
\text { (VP) }\end{array}$ \\
\hline $12 / 31 / 93$ & EUA & GLATFELTER (P.H.) COMPANY & 1 & 31.72 & 1 & $-2.1 \%$ & 1 & 0.10 & 1 & 0.18 \\
\hline $09 / 30 / 93$ & EUA & ROCK TENN CO & 2 & 18.68 & 17 & $-4.9 \%$ & & & 2 & 0.22 \\
\hline $12 / 31 / 93$ & EUA & KIMBERLY-CLARK & 3 & 10.83 & 14 & $-4.4 \%$ & 2 & 0.18 & 10 & 0.64 \\
\hline $12 / 31 / 93$ & EUA & SONOCO PRODUCTS COMPANY & 4 & 10.12 & 15 & $-4.5 \%$ & 3 & 0.22 & 8 & 0.62 \\
\hline $12 / 31 / 93$ & EUA & WILLAMETTE INDUSTRIES, INC & 5 & 7.06 & 9 & $-3.9 \%$ & 4 & 0.36 & 16 & 0.80 \\
\hline $12 / 31 / 93$ & Brasil & PAPEL SIMAO (Votorantim C P) & 27 & 1.91 & 39 & $-11.5 \%$ & 19 & 0.75 & 3 & 0.28 \\
\hline $12 / 31 / 93$ & Brasil & Suzano & 31 & 1.68 & 31 & $-7.9 \%$ & 29 & 1.59 & 11 & 0.65 \\
\hline $12 / 31 / 93$ & Brasil & Klabin & 32 & 1.60 & 37 & $-9.8 \%$ & 21 & 0.96 & 6 & 0.55 \\
\hline $12 / 31 / 93$ & Brasil & Aracruz & 36 & 1.15 & 41 & $-16.1 \%$ & 14 & 0.62 & 9 & 0.63 \\
\hline $12 / 31 / 95$ & EUA & WILLAMETTE INDUSTRIES, INC & 1 & 16.10 & 10 & $-4.2 \%$ & 7 & 0.33 & 10 & 0.63 \\
\hline $12 / 31 / 95$ & EUA & GLATFELTER (P.H.) COMPANY & 2 & 14.66 & 7 & $-3.8 \%$ & 3 & 0.22 & 8 & 0.53 \\
\hline 09/30/95 & EUA & ROCK TENN CO & 3 & 14.25 & 14 & $-4.5 \%$ & 2 & 0.21 & 3 & 0.38 \\
\hline $12 / 31 / 95$ & EUA & MEAD CORPORATION (THE) & 4 & 12.00 & 21 & $-4.8 \%$ & 5 & 0.32 & 4 & 0.40 \\
\hline $12 / 31 / 95$ & Brasil & Votorantim C P & 5 & 11.91 & 36 & $-6.8 \%$ & 10 & 0.46 & 1 & 0.21 \\
\hline $12 / 31 / 95$ & Brasil & Aracruz & 6 & 11.44 & 3 & $-2.8 \%$ & 23 & 0.84 & 13 & 0.65 \\
\hline $12 / 31 / 95$ & Brasil & Klabin & 22 & 7.44 & 25 & $-5.0 \%$ & 28 & 1.11 & 6 & 0.52 \\
\hline $12 / 31 / 95$ & Brasil & Suzano & 26 & 6.70 & 6 & $-3.7 \%$ & 26 & 1.06 & 7 & 0.53 \\
\hline $12 / 31 / 97$ & EUA & KIMBERLY-CLARK & 1 & 15.06 & 15 & $-4.1 \%$ & 1 & 0.09 & 4 & 0.53 \\
\hline $12 / 31 / 97$ & EUA & RAYONIER, INC. & 2 & 9.66 & 10 & $-4.0 \%$ & 5 & 0.36 & 14 & 0.66 \\
\hline $12 / 31 / 97$ & EUA & CHESAPEAKE CORPORATION & 3 & 9.18 & 4 & $-3.4 \%$ & 14 & 0.54 & 20 & 0.88 \\
\hline $12 / 31 / 97$ & EUA & SONOCO PRODUCTS COMPANY & 4 & 8.74 & 12 & $-4.1 \%$ & 2 & 0.25 & 24 & 0.95 \\
\hline $12 / 31 / 97$ & EUA & GLATFELTER (P.H.) COMPANY & 5 & 6.85 & 19 & $-4.5 \%$ & 3 & 0.32 & 16 & 0.74 \\
\hline $12 / 31 / 97$ & Brasil & Klabin & 29 & 3.06 & 26 & $-5.4 \%$ & 35 & 2.67 & 10 & 0.60 \\
\hline $12 / 31 / 97$ & Brasil & Aracruz & 34 & 2.17 & 34 & $-8.2 \%$ & 23 & 0.90 & 9 & 0.60 \\
\hline $12 / 31 / 97$ & Brasil & Votorantim C P & 35 & 2.15 & 39 & $-12.2 \%$ & 24 & 0.98 & 2 & 0.39 \\
\hline $12 / 31 / 97$ & Brasil & Suzano & 36 & 1.77 & 33 & $-7.8 \%$ & 36 & 3.76 & 17 & 0.77 \\
\hline
\end{tabular}

FONTES: ver FONTES da Tabela 1.

A Tabela 3 mostra o custo das dívidas (CD) das empresas calculado de duas formas: a primeira considera o benefício fiscal do imposto de renda pela alíquota oficial (IRo), enquanto a segunda desconsidera este benefício fiscal (IRn). Adicionalmente, a tabela apresenta o nível de alavancagem (B/S) calculado considerando o PL a valor histórico (VP) e a valor de mercado (VM). Esta tabela não deixa dúvidas a respeito do alto custo do capital de terceiros das empresas brasileiras quando comparadas às demais. Quando é examinado o endividamento $(\mathrm{B} / \mathrm{S})$ considerando o PL a valor histórico, vê-se que a empresa brasileira é pouco endividada. Aqui, o alto CD da empresa brasileira é explicado de forma oposta à lógica financeira. Geralmente, as empresas têm alto CD quando são altamente alavancadas e, por conta do risco de alta alavancagem, pagam uma alta taxa de captação. No caso da empresa brasileira, ela é pouco endividada porque não há recursos de longo prazo disponíveis e, quando os há, são caros. O baixo endividamento em termos históricos mostra que a empresa brasileira foi majoritariamente financiada por recursos de capital próprio e não de terceiros. Por outro lado, a maior alavancagem quando considerado o PL a valor de mercado pode, como comentado anteriormente, mostrar a desvalorização do capital próprio das empresas brasileiras durante os anos 90 . 
TABELA 3

ANÁLISE DO CUSTO DA DÍVIDA - 1993, 1995 E 1997

\begin{tabular}{|c|c|c|c|c|c|c|c|c|c|c|}
\hline Data & País & Empresa & Clas & $\begin{array}{r}\text { CD } \\
\text { (IRo) }\end{array}$ & Clas & $\begin{array}{r}\text { CD } \\
\text { (IRn) }\end{array}$ & Clas & $\begin{array}{l}\text { B / S } \\
\text { (VP) }\end{array}$ & Clas & $\begin{array}{l}\text { B / S } \\
\text { (VM) }\end{array}$ \\
\hline $12 / 31 / 93$ & EUA & GLATFELTER (P.H.) COMPANY & 1 & $-2.1 \%$ & 2 & $-3.5 \%$ & 1 & 0.18 & 1 & 0.10 \\
\hline $03 / 31 / 94$ & Japão & DAIO PAPER CORPORATION & 2 & $-2.7 \%$ & 5 & $-5.6 \%$ & 36 & 3.11 & 32 & 2.66 \\
\hline $12 / 31 / 93$ & N Zelândia & CARTER HOLT HARVEY LTD. & 3 & $-2.8 \%$ & 3 & $-4.2 \%$ & 17 & 0.83 & 15 & 0.63 \\
\hline $12 / 26 / 93$ & EUA & WEYERHAEUSER COMPANY & 4 & $-2.9 \%$ & 4 & $-4.9 \%$ & 30 & 1.51 & 16 & 0.64 \\
\hline $12 / 31 / 93$ & Canada & NORANDA FOREST INC. & 5 & $-3.3 \%$ & 1 & $-3.3 \%$ & 27 & 1.36 & 27 & 1.35 \\
\hline $12 / 31 / 93$ & Brasil & Suzano & 31 & $-7.9 \%$ & 36 & $-11.2 \%$ & 11 & 0.65 & 29 & 1.59 \\
\hline $12 / 31 / 93$ & Brasil & Klabin & 37 & $-9.8 \%$ & 37 & $-12.5 \%$ & 6 & 0.55 & 21 & 0.96 \\
\hline $12 / 31 / 93$ & Brasil & PAPEL SIMAO (Votorantim C P) & 39 & $-11.5 \%$ & 40 & $-18.7 \%$ & 3 & 0.28 & 19 & 0.75 \\
\hline $12 / 31 / 93$ & Brasil & Aracruz & 41 & $-16.1 \%$ & 41 & $-19.3 \%$ & 9 & 0.63 & 14 & 0.62 \\
\hline $12 / 31 / 95$ & EUA & TEMPLE-INLAND INC. & 1 & $-1.4 \%$ & 1 & $-2.3 \%$ & 33 & 1.67 & 30 & 1.29 \\
\hline 03/31/96 & Japão & DAIO PAPER CORPORATION & 2 & $-1.8 \%$ & 2 & $-3.7 \%$ & 37 & 2.85 & 34 & 1.90 \\
\hline $12 / 31 / 95$ & Brasil & Aracruz & 3 & $-2.8 \%$ & 3 & $-4.2 \%$ & 13 & 0.65 & 23 & 0.84 \\
\hline $12 / 31 / 95$ & N Zelândia & CARTER HOLT HARVEY LTD. & 4 & $-3.3 \%$ & 4 & $-5.0 \%$ & 5 & 0.45 & 6 & 0.33 \\
\hline $12 / 31 / 95$ & EUA & WEYERHAEUSER COMPANY & 5 & $-3.6 \%$ & 7 & $-5.9 \%$ & 30 & 1.18 & 17 & 0.62 \\
\hline $12 / 31 / 95$ & Brasil & Suzano & 6 & $-3.7 \%$ & 5 & $-5.6 \%$ & 7 & 0.53 & 26 & 1.06 \\
\hline $12 / 31 / 95$ & Brasil & Klabin & 25 & $-5.0 \%$ & 18 & $-7.4 \%$ & 6 & 0.52 & 28 & 1.11 \\
\hline $12 / 31 / 95$ & Brasil & Votorantim C P & 36 & $-6.8 \%$ & 35 & $-10.2 \%$ & 1 & 0.21 & 10 & 0.46 \\
\hline $03 / 31 / 97$ & Japão & DAIO PAPER CORPORATION & 1 & $-1.5 \%$ & 2 & $-3.2 \%$ & 35 & 2.53 & 34 & 2.41 \\
\hline $12 / 31 / 97$ & EUA & TEMPLE-INLAND INC. & 2 & $-1.8 \%$ & 1 & $-3.0 \%$ & 33 & 1.71 & 29 & 1.22 \\
\hline $12 / 31 / 97$ & EUA & INTERNATIONAL PAPER COMPANY & 3 & $-3.0 \%$ & 4 & $-5.1 \%$ & 19 & 0.86 & 20 & 0.74 \\
\hline $12 / 31 / 97$ & EUA & CHESAPEAKE CORPORATION & 4 & $-3.4 \%$ & 7 & $-5.6 \%$ & 20 & 0.88 & 14 & 0.54 \\
\hline $12 / 31 / 97$ & EUA & WILLAMETTE INDUSTRIES, INC & 5 & $-3.5 \%$ & 8 & $-5.8 \%$ & 27 & 1.02 & 17 & 0.57 \\
\hline $12 / 31 / 97$ & Brasil & Klabin & 26 & $-5.4 \%$ & 25 & $-7.6 \%$ & 10 & 0.60 & 35 & 2.67 \\
\hline $12 / 31 / 97$ & Brasil & Suzano & 33 & $-7.8 \%$ & 36 & $-11.3 \%$ & 17 & 0.77 & 36 & 3.76 \\
\hline $12 / 31 / 97$ & Brasil & Aracruz & 34 & $-8.2 \%$ & 38 & $-12.2 \%$ & 9 & 0.60 & 23 & 0.90 \\
\hline $12 / 31 / 97$ & Brasil & Votorantim C P & 39 & $-12.2 \%$ & 39 & $-18.2 \%$ & 2 & 0.39 & 24 & 0.98 \\
\hline
\end{tabular}

FONTES: ver FONTES da Tabela 1.

A Tabela 4 confirma o que foi anteriormente mencionado a respeito do nível de alavancagem das empresas aqui estudadas. Pela Tabela 4, podese confirmar a pouca participação que teve o capital de terceiros em empresas de países como Brasil, Chile e África do Sul. A maioria destas empresas se encaixa entre as primeiras, considerando-se o menor nível de alavancagem como critério de classificação. Vale destacar o caso da empresa sul-africana, a Sappi, que aumenta consideravelmente o nível de alavancagem durante o período estudado. Este aumento coincide com uma ampla estratégia de crescimento e internacionalização da empresa. Excluindo-se as brasileiras, as empresas que aparecem entre as primeiras por este critério de classificação são empresas que tiveram baixo custo de captação no período estudado. 
TABELA 4

ANÁLISE DO ENDIVIDAMENTO, PL A VALOR DE LIVRO - 1993, 1995 E 1997

\begin{tabular}{|c|c|c|c|c|c|c|}
\hline Data & País & Empresa & Clas & B / S (VP) & Clas & B / S (VM) \\
\hline $12 / 31 / 93$ & EUA & GLATFELTER (P.H.) COMPANY & 1 & 0.18 & 1 & 0.10 \\
\hline 09/30/93 & EUA & ROCK TENN CO & 2 & 0.22 & & \\
\hline $12 / 31 / 93$ & Brasil & PAPEL SIMAO (Votorantim C P PN) & 3 & 0.28 & 19 & 0.75 \\
\hline $02 / 28 / 94$ & África Sul & SAPPI LIMITED & 4 & 0.41 & 7 & 0.47 \\
\hline $12 / 31 / 93$ & Chile & ARAUCO \& CONSTITUTION PULP INC & 5 & 0.53 & & \\
\hline $12 / 31 / 93$ & Brasil & Klabin & 6 & 0.55 & 21 & 0.96 \\
\hline $12 / 31 / 93$ & Brasil & Aracruz & 9 & 0.63 & 14 & 0.62 \\
\hline $12 / 31 / 93$ & Brasil & Suzano & 11 & 0.65 & 29 & 1.59 \\
\hline $12 / 31 / 95$ & Brasil & Votorantim C P & 1 & 0.21 & 10 & 0.46 \\
\hline $12 / 31 / 95$ & Chile & ARAUCO \& CONSTITUTION PULP INC & 2 & 0.36 & & \\
\hline 09/30/95 & EUA & ROCK TENN CO & 3 & 0.38 & 2 & 0.21 \\
\hline $12 / 31 / 95$ & EUA & MEAD CORPORATION (THE) & 4 & 0.40 & 5 & 0.32 \\
\hline $12 / 31 / 95$ & N Zelândia & CARTER HOLT HARVEY LTD. & 5 & 0.45 & 6 & 0.33 \\
\hline $12 / 31 / 95$ & Brasil & Klabin & 6 & 0.52 & 28 & 1.11 \\
\hline $12 / 31 / 95$ & Brasil & Suzano & 7 & 0.53 & 26 & 1.06 \\
\hline $12 / 31 / 95$ & Brasil & Aracruz & 13 & 0.65 & 23 & 0.84 \\
\hline $12 / 31 / 97$ & N Zelândia & CARTER HOLT HARVEY LTD. & 1 & 0.39 & 6 & 0.36 \\
\hline $12 / 31 / 97$ & Brasil & Votorantim C P & 2 & 0.39 & 24 & 0.98 \\
\hline $12 / 31 / 97$ & Chile & ARAUCO \& CONSTITUTION PULP INC & 3 & 0.48 & & \\
\hline $12 / 31 / 97$ & EUA & KIMBERLY-CLARK CORPORATION & 4 & 0.53 & 1 & 0.09 \\
\hline $12 / 31 / 97$ & Canada & ABITIBI-CONSOLIDATED INC & 5 & 0.57 & 4 & 0.32 \\
\hline $12 / 31 / 97$ & Brasil & Aracruz & 9 & 0.60 & 23 & 0.90 \\
\hline $12 / 31 / 97$ & Brasil & Klabin & 10 & 0.60 & 35 & 2.67 \\
\hline $12 / 31 / 97$ & Brasil & Suzano & 17 & 0.77 & 36 & 3.76 \\
\hline
\end{tabular}

FONTES: ver FONTES da Tabela 1.

Na Tabela 5, será analisado comparativamente o tamanho das empresas. Adicionalmente, será apresentado o retorno sobre o investimento (PL a valor de mercado) aberto em seus componentes - margem e giro. As vendas de empresas expressas em outras moedas foram convertidas em dólar pelo valor médio do período, à exceção das empresas brasileiras nos anos em que apresentaram as demonstrações financeiras de acordo com os princípios da correção integral, quando foi utilizado o dólar de final de período.

A Tabela 5 mostra quão pequenas são as empresas brasileiras, mesmo considerando o expressivo crescimento que tiveram nas suas vendas de 1993 a 1997. Em 1997, a décima maior empresa da amostra faturava 4.3 vezes mais do que a maior empresa brasileira e a quinta maior empresa da amostra faturava praticamente 10 vezes mais do que a maior brasileira. Vale notar, também, o baixo giro das empresas brasileiras, mesmo considerando o investimento a valor de mercado. Neste ponto, destaca-se o baixíssimo giro da Aracruz, o que é grandemente compensado pela altíssima margem que a empresa conseguiu. Em todos os períodos, a Aracruz foi a empresa de maiores margens, o que, em parte, pode ser explicado pelo segmento de celulose em que opera.

Por último, pode-se verificar que todas as empresas que apareceram entre as cinco primeiras pelo critério de vendas foram empresas que captaram recursos a baixo custo no mercado financeiro internacional. 


\section{TABELA 5}

\section{ANÁLISE DOTAMANHO, POR VENDAS - 1993, 1995 E 1997}

\begin{tabular}{|c|c|c|c|c|c|c|c|c|}
\hline Data & País & Empresa & Clas & V (US\$ mil) & Clas & $\begin{array}{r}\text { ROI (IRo, } \\
\text { VM) }\end{array}$ & $\begin{array}{l}\text { V / I } \\
\text { (VM) }\end{array}$ & $\begin{array}{r}\text { Laj / V } \\
\text { (IRo) }\end{array}$ \\
\hline $12 / 31 / 93$ & EUA & INTERNATIONAL PAPER & 1 & $13,685,000$ & 16 & $3.62 \%$ & 0.98 & $3.69 \%$ \\
\hline $12 / 31 / 93$ & EUA & GEORGIA-PACIFIC & 2 & $12,330,000$ & 22 & $2.57 \%$ & 1.09 & $2.35 \%$ \\
\hline $12 / 26 / 93$ & EUA & WEYERHAEUSER COMPANY & 3 & $9,544,792$ & 6 & $4.65 \%$ & 0.63 & $7.33 \%$ \\
\hline $12 / 31 / 93$ & Finlândia & UPM-KYMMENE OYJ & 4 & $7,696,147$ & & & & $5.89 \%$ \\
\hline $12 / 31 / 93$ & EUA & KIMBERLY-CLARK & 5 & $6,972,900$ & 2 & $6.01 \%$ & 0.71 & $8.52 \%$ \\
\hline $12 / 31 / 93$ & Brasil & Klabin & 33 & 606,213 & 27 & $2.03 \%$ & 0.54 & $3.80 \%$ \\
\hline $12 / 31 / 93$ & Brasil & Suzano & 35 & 576,538 & 32 & $-0.55 \%$ & 0.36 & $-1.54 \%$ \\
\hline $12 / 31 / 93$ & Brasil & Aracruz & 39 & 310,728 & 15 & $3.83 \%$ & 0.14 & $27.23 \%$ \\
\hline $12 / 31 / 93$ & Brasil & PAPEL SIMAO (Votorantim C P) & 41 & 239,366 & 5 & $4.82 \%$ & 0.74 & $6.48 \%$ \\
\hline $12 / 31 / 95$ & EUA & INTERNATIONAL PAPER & 1 & $19,797,000$ & 22 & $9.26 \%$ & 1.15 & $8.08 \%$ \\
\hline $12 / 31 / 95$ & EUA & GEORGIA-PACIFIC & 2 & $14,292,000$ & 16 & $11.01 \%$ & 1.25 & $8.78 \%$ \\
\hline $12 / 31 / 95$ & EUA & KIMBERLY-CLARK & 3 & $13,788,600$ & 31 & $6.48 \%$ & 0.54 & $11.98 \%$ \\
\hline $12 / 31 / 95$ & Finlândia & UPM-KYMMENE OYJ & 4 & $12,535,324$ & & & & $13.68 \%$ \\
\hline $12 / 31 / 95$ & EUA & WEYERHAEUSER COMPANY & 5 & $11,788,000$ & 23 & $9.19 \%$ & 0.85 & $10.84 \%$ \\
\hline $12 / 31 / 95$ & Brasil & Klabin & 30 & $1,284,813$ & 12 & $12.01 \%$ & 0.83 & $14.53 \%$ \\
\hline $12 / 31 / 95$ & Brasil & Suzano & 35 & $1,018,016$ & 28 & $7.28 \%$ & 0.42 & $17.22 \%$ \\
\hline $12 / 31 / 95$ & Brasil & Aracruz & 37 & 801,115 & 10 & $12.58 \%$ & 0.26 & $48.56 \%$ \\
\hline $12 / 31 / 95$ & Brasil & Votorantim C P & 38 & 793,428 & 35 & $5.20 \%$ & 0.87 & $5.99 \%$ \\
\hline $12 / 31 / 97$ & EUA & INTERNATIONAL PAPER & 1 & $20,096,000$ & 21 & $4.02 \%$ & 0.88 & $4.54 \%$ \\
\hline $12 / 31 / 97$ & EUA & GEORGIA-PACIFIC & 2 & $13,094,000$ & 32 & $2.51 \%$ & 1.18 & $2.14 \%$ \\
\hline $12 / 31 / 97$ & EUA & KIMBERLY-CLARK & 3 & $12,546,600$ & 15 & $5.00 \%$ & 0.42 & $11.89 \%$ \\
\hline $12 / 28 / 97$ & EUA & WEYERHAEUSER COMPANY & 4 & $11,210,000$ & 25 & $3.58 \%$ & 0.75 & $4.76 \%$ \\
\hline $12 / 31 / 97$ & Finlândia & UPM-KYMMENE OYJ & 5 & $9,709,520$ & 1 & $8.61 \%$ & 0.81 & $10.69 \%$ \\
\hline $12 / 31 / 97$ & Brasil & Suzano & 29 & $1,284,678$ & 7 & $7.32 \%$ & 0.63 & $11.67 \%$ \\
\hline $12 / 31 / 97$ & Brasil & Klabin PN & 32 & $1,052,008$ & 23 & $3.78 \%$ & 0.77 & $4.90 \%$ \\
\hline $12 / 31 / 97$ & Brasil & Votorantim C P & 36 & 634,655 & 2 & $8.25 \%$ & 0.42 & $19.66 \%$ \\
\hline $12 / 31 / 97$ & Brasil & Aracruz & 38 & 497,988 & 18 & $4.69 \%$ & 0.17 & $27.59 \%$ \\
\hline
\end{tabular}

FONTES: ver FONTES da Tabela 1.

A próxima tabela apresenta alguns indicadores de risco. Aqui, a preocupação é com a possibilidade de o fluxo de caixa de uma empresa ser insuficiente para cobrir os seus encargos financeiros. A idéia é que um fluxo de caixa que apresente uma elevada variabilidade ao longo do tempo pode, em algum momento, cair abaixo do nível mínimo para cobrir as despesas financeiras. A Tabela 6 apresenta um índice que relaciona, para o período de três anos, as despesas financeiras máximas, o fluxo de caixa médio e o seu desvio padrão. $O$ índice, denominado $Z$, assume o fluxo de caixa como tendo uma distribuição normal e mostra a posição das despesas financeiras máximas nesta distribuição. Quanto mais negativo o valor de $Z$, mais à esquerda estão as despesas financeiras (o máximo que ocorreu em três anos) em relação à média do fluxo de caixa em três anos, significando uma baixa probabilidade de superarem o fluxo de caixa. Adicionalmente, será apresentado um índice de cobertura das despesas financeiras e a classificação de risco segundo Minsky. No índice de cobertura apresentado, ao invés de simplesmente se fazer o cálculo da relação entre o fluxo de caixa e as despesas financeiras, como foi feito na Tabela 2, é somado ao fluxo de caixa o saldo de tesouraria (ST), que representa um estoque de recursos financeiros potencialmente utilizáveis para cobrir parte das despesas financeiras.

Apesar de apresentar casos de classificações opostas àquelas decorrentes de outros índices de risco - como o índice de cobertura e o de Minsky, também apresentados na Tabela 6 - considera-se este indicador mais expressivo do risco de não cobertura das despesas financeiras pelo fluxo de caixa da empresa. Quando comparado com o Coeficiente de 
Variação - CV, o Z apresenta, além do elemento de volatilidade do fluxo de caixa, uma relação entre as despesas financeiras e o nível médio de fluxo de caixa. Quanto mais numerosos forem os casos de empresas com alto nível de endividamento e, por conseqüência, com pesada carga de despesas financeiras, maior será a diferença entre o CV e o Z e, então, a preferência pelo Z. Um bom argumento em defesa deste indicador é o fato de todas as empresas que apareceram entre as cinco primeiras na Tabela 6 terem sido as que captaram recursos com baixo custo. Nesta tabela, pode-se perceber que as empresas brasileiras apresentaram, consistentemente, ao longo de todo o período, uma baixa classificação segundo o índice Z, confirmando o seu nível de risco elevado.

\section{TABELA 6}

ANÁLISE DO ÍNDICE Z - 1993, 1995 E 1997

\begin{tabular}{|c|c|c|c|c|c|c|c|}
\hline Data & País & Empresa & Clas & $\mathbf{Z}$ & Clas & $\begin{array}{l}+ \text { FC) } \\
\text { / dFin }\end{array}$ & Minsky \\
\hline $12 / 31 / 93$ & EUA & CHESAPEAKE CORPORATION & 1 & -51.63 & 12 & 3.75 & hedge \\
\hline $12 / 31 / 93$ & EUA & UNION CAMP CORPORATION & 2 & -35.27 & 31 & 0.42 & speculative \\
\hline $12 / 31 / 93$ & EUA & KIMBERLY-CLARK & 3 & -27.22 & 8 & 4.44 & hedge \\
\hline $12 / 31 / 93$ & EUA & INTERNATIONAL PAPER & 4 & -25.37 & 35 & -0.25 & speculative \\
\hline $10 / 31 / 93$ & EUA & WESTVACO CORPORATION & 5 & -11.94 & 6 & 5.32 & hedge \\
\hline $12 / 31 / 93$ & Brasil & Klabin & 24 & -1.89 & 32 & 0.12 & speculative \\
\hline $12 / 31 / 93$ & Brasil & Suzano & 26 & -1.14 & 29 & 0.66 & speculative \\
\hline $12 / 31 / 93$ & Brasil & PAPEL SIMAO (Votorantim C P) & 33 & -0.15 & 34 & -0.02 & speculative \\
\hline $12 / 31 / 93$ & Brasil & Aracruz & 36 & 0.37 & 39 & -0.66 & speculative \\
\hline $12 / 31 / 95$ & EUA & RAYONIER, INC. & 1 & -7.42 & 10 & 10.13 & hedge \\
\hline $12 / 31 / 95$ & EUA & SONOCO PRODUCTS COMPANY & 2 & -6.31 & 13 & 9.27 & hedge \\
\hline 03/31/96 & Japão & DAIO PAPER CORPORATION & 3 & -5.03 & 40 & -1.35 & speculative \\
\hline $09 / 30 / 95$ & EUA & ROCK TENN CO & 4 & -4.85 & 5 & 14.69 & hedge \\
\hline $12 / 31 / 95$ & EUA & POTLATCH CORPORATION & 5 & -4.55 & 20 & 7.17 & hedge \\
\hline $12 / 31 / 95$ & Brasil & Suzano & 26 & -1.88 & 31 & 3.44 & hedge \\
\hline $12 / 31 / 95$ & Brasil & Klabin & 29 & -1.49 & 26 & 5.80 & hedge \\
\hline $12 / 31 / 95$ & Brasil & Aracruz & 31 & -1.22 & 3 & 15.27 & hedge \\
\hline $12 / 31 / 95$ & Brasil & Votorantim C P & 34 & -1.05 & 2 & 15.63 & hedge \\
\hline $06 / 30 / 97$ & N Zelândia & FLETCHER CHALLENGE PAPER & 1 & -303.05 & 12 & 6.10 & hedge \\
\hline $12 / 31 / 97$ & EUA & SONOCO PRODUCTS COMPANY & 2 & -17.17 & 7 & 7.93 & hedge \\
\hline $12 / 31 / 97$ & EUA & GLATFELTER (P.H.) COMPANY & 3 & -13.20 & 8 & 7.71 & hedge \\
\hline $12 / 31 / 97$ & EUA & KIMBERLY-CLARK & 4 & -12.03 & 2 & 10.79 & hedge \\
\hline 09/30/97 & EUA & ROCK TENN CO & 5 & -10.93 & 21 & 3.31 & hedge \\
\hline $12 / 31 / 97$ & Brasil & Klabin PN & 26 & -2.65 & 31 & 1.08 & hedge \\
\hline $12 / 31 / 97$ & Brasil & Aracruz PNB & 31 & -2.08 & 37 & -1.90 & speculative \\
\hline $12 / 31 / 97$ & Brasil & Suzano PN & 32 & -2.00 & 32 & 0.86 & speculative \\
\hline $12 / 31 / 97$ & Brasil & Votorantim C P PN & 34 & -1.82 & 15 & 4.55 & hedge \\
\hline
\end{tabular}

FONTES: ver FONTES da Tabela 1.

\section{AS EMPRESAS QUE PAGARAM CARO, ALÉM DAS BRASILEIRAS}

Nesta pesquisa, foram identificadas, além das brasileiras, sete empresas que tiveram alto custo de captação no período estudado. Estas empresas foram as canadenses Repap New Brunswick e Domtar e as americanas Fort Howard, Gaylord, Repap Wisconsin, Riverwood e Stone
Container. Vários dos indicadores analisados acima já tinham permitido verificar que estas empresas apresentaram problemas em vários itens, como rentabilidade e alavancagem. Neste item, com o objetivo de detalhar um pouco mais o funcionamento dos mercados de dívidas, serão analisados alguns aspectos adicionais destas empresas procurando explicar o alto custo de captação que tiveram. 
Começando pela americana Fort Howard, percebe-se que se trata de uma empresa com fortes prejuízos ao longo de praticamente todo o período estudado. A empresa, que em 1989 já apresentava prejuízo acumulado em seu balanço, continuou apresentando fortes prejuízos até 1994. Eles foram tão expressivos que, a partir de 1992, a empresa passou a apresentar patrimônio líquido negativo, que persistiu até o balanço de 1996. Em agosto de 1997, a empresa foi fundida com uma subsidiária da James River Corporation, tornando-se uma subsidiária $100 \%$ da nova controladora. Nesta mesma data o nome da James River Corporation mudou-se para Fort James Corporation (Fort James, Relatório Financeiro, 1997:60).

Esta empresa americana, com passivo contábil a descoberto, captou recursos nos mercados americano e internacional em 1993 e 1994 em condições melhores do que o fizeram quaisquer das brasileiras. Segundo o The Wall Street Journal - TWSJ, a "Fort Howard e muitas outras empresas altamente alavancadas estavam repondo bilhões de dólares em dívidas bancárias vendendo junk bonds através das "Wall Street securities firms" (TWSJ, 18.maio.1993). Em 1993, a Fort Howard ofereceu um rendimento de 372 pontos acima dos títulos do Tesouro americano para uma captação de 9 anos, enquanto a Aracruz pagou 391 pontos para uma captação de 5 anos, a Suzano 516 pontos (8 anos) e a Klabin 687 e 468 pontos ( 3 e 8 anos) em duas emissões. Em 1994, a Fort Howard pagou 297 pontos (10 anos), enquanto Aracruz pagou 426 pontos (3 anos) e Klabin 446 pontos (8 anos).

A Gaylord e a Repap Wisconsin, outras empresas americanas que tiveram alto custo de captação no período estudado, também não apresentaram uma situação financeira muito saudável. Pelos dados obtidos, de 1989 a 1997, pode-se verificar que a Gaylord apresentou prejuízo de 1990 a 1994 e em 1997 e patrimônio líquido negativo em 1991, 1992 e 1994. A Repap Wisconsin, subsidiária de Repap USA, uma unidade americana do grupo canadense Repap Enterprises, apresentou prejuízos em praticamente todo o período estudado. De 1990 a 1996, a empresa apresentou lucro líquido em apenas um ano - 1995, valendo-se de preços de celulose e papel que estavam no seu pico. Em outubro de 1997, a Repap Enterprises vendeu a Repap USA e suas subsidiárias para a Consolidated Papers (SEC-EDGAR, Form 8K, 1.out.1997). Após a venda, a Repap Wisconsin passou a se chamar Inter Lake Wisconsin.

A Riverwood, a quarta empresa do grupo alto custo, teve uma curta história como empresa pública (aberta) no mercado norte americano. Incorporada em 1989 (Moody's Bond record, 1994:6309), a empresa passou a ser listada em junho de 1992 na Bolsa de Valores de Nova lorque (NYSE) (TWSJ, 22.jun.1992). Em 1993 e 1994, a empresa apresentou baixíssimos níveis de lucro, respectivamente, $0.3 \%$ e $0.9 \%$, considerando-se o PL a valor de mercado, e $0.7 \%$ e $2 \%$, considerando-se o PL a valor histórico. Em março de 1996, com a participação da gerência e liderada pela "investment firm Clayton, Dubilier \& Rice", a empresa tornou-se fechada através de um grande LBO. O grupo de investidores pagou US\$1.6 bilhões pela empresa e assumiu US\$1.1 bilhões de dívidas da empresa (TWSJ, 28.mar.1996; e NYT Events Edition, 27.out.1995). Parte desta operação, US $\$ 1.55$ bilhões, seria financiada pelo Chemical Banking Corp, que contava com sua capacidade de levantar US $\$ 650$ milhões através de high-yield securities (TWSJ, 27.out.1995). Apesar de não se saber se este arranjo foi confirmado quando do fechamento da operação, sabe-se que, em março de 1996, o Chemical Banking liderou duas emissões de bonds da Riverwood no total dos US $\$ 650$ milhões, o que confirma boa parte da história. No próprio ano de 1996, a venda de ativos e o desmonte da empresa já começaram. Em outubro, a empresa vendeu o seu segmento americano de florestas e madeira por aproximadamente US $\$ 550$ milhões (Disclosure Info Service-microfiche, Riverwood, form 10K, 12.dez.1996). Pode-se observar que mais uma empresa que captou recursos com custos semelhantes ao das empresas brasileiras foi uma com pouca tradição no mercado financeiro americano e internacional, e com problemas financeiros que, num curto espaço de tempo, levariam-na a ser adquirida por um grupo de investidores.

A última empresa americana constante do grupo de alto custo foi a Stone Container. Apesar de ser uma empresa com forte tradição no mercado americano (empresa aberta desde 1947), acumulou problemas financeiros ao longo de todos os anos 
90. A evolução do nível de alavancagem da Stone Container pode ser confirmada pelos números abaixo. Primeiro, é apresentado o indicador B/S com o PL a valor histórico. Em 1991 o indicador era 2.7; em 1994, 5.3; e em 1997, 7.9. Quando calculado com o PL a valor de mercado, a relação entre dívidas e capital próprio da empresa foi 2.3 em 1991, 2.97 em 1994 e 3.9 em 1997. Os resultados desta empresa não poderiam ser diferentes. Com exceção de 1995, o ano de alta dos preços de celulose e papel, de 1991 a 1997 a empresa apresentou fortes prejuízos, o que fez com que terminasse 1997 o ano que antecedeu a sua fusão com a Jefferson Smurfit - com a conta de prejuízos acumulados em US $\$ 510$ milhões e um patrimônio líquido de apenas US\$162 milhões. Ou seja, tratava-se de mais uma empresa "quebrada" que, para conseguir recursos nos mercados financeiros, teve de pagar tanto quanto uma empresa brasileira.

Serão examinadas agora as duas empresas canadenses da amostra que captaram recursos por um alto custo durante o período estudado. Primeiro será analisada a Repap New Brunswick, uma das empresas do grupo canadense Repap Enterprises. Não muito diferente da Repap Wisconsin - principal empresa americana do grupo - a Repap New Brunswick, de 1992 a 1997, apenas não apresentou prejuízo no ano de 1995, o ano dos altos preços da celulose e do papel. Os fortes prejuízos da empresa fizeram com que chegasse a $1997 \mathrm{com}$ patrimônio líquido negativo. Em 1997, a alavancagem com o PL a valor de mercado foi calculada utilizando-se o valor de mercado de Repap Enterprises, a empresa mãe, que praticamente apenas possuía a Repap New Brunswick. Até março de 1999, a Repap New Brunswick era a única subsidiária manufatureira ainda mantida pela Repap Enterprises.

Uma das saídas dos acionistas da Repap foi arrumar, com a concordância da gerência da Avenor, a venda da empresa para esta última. No entanto, a venda que havia sido aprovada por $92 \%$ dos acionistas da Repap foi simplesmente rejeitada por $74 \%$ dos acionistas da Avenor. O comentário do The Wall Street Journal (1997) ilustra perfeitamente a situação desta empresa. Para não perder a força das próprias palavras do correspondente do TWSJ, foi mantida a citação em inglês: "Avenor Inc. shareholders overwhelmingly rejected the proposed acquisition of Repap Enterprises Inc., delivering a rebuke to Avenor's management and leaving debtstrapped Repap to find another rescuer" (TWSJ, 27.mar.1997:B4).

A segunda empresa canadense do grupo alto custo foi a Domtar. A Domtar, diferentemente das empresas analisadas anteriormente, captou recursos com alto e baixo custo. Em 1992 e 1993, a empresa captou com alto custo, pagando respectivamente 449 e 608 pontos de rendimento acima dos títulos do Tesouro americano. Em 1996, a empresa captou pagando 192 pontos. Ou seja, trata-se de um caso ainda mais curioso, ou seja, um caso de uma empresa que "encontrou a salvação". Os resultados da empresa durante o período analisado justificam a mudança deste custo de captação. De 1990 a 1993, a empresa apresentou fortes prejuízos. A soma dos prejuízos deste período representava aproximadamente $71 \%$ do seu patrimônio líquido, em termos históricos, de 1989. No entanto, a partir de 1994, a empresa apresenta resultados positivos em uma série de índices que permitem observar mudanças profundas na sua estrutura financeira. Comparando o nível de alavancagem (B/S), considerando-se o PL a valor histórico, temos 1.3 para 1993, 1.2 para 1995, e 0.6 para 1997. O nível de alavancagem quando calculado com o PL a valor de mercado foi 1.8 em 1992, 0.9 em 1995, e 0.5 em 1997. A relação entre o fluxo de caixa e as despesas financeiras evidencia ainda mais a melhoria da situação da empresa. Esta relação foi $0.5 \mathrm{em}$ 1992, 5.7 em 1995, e 3.9 em 1997. Não foi à toa a profunda diferença entre o custo de captação desta empresa em 1992/93 e 1996.

A análise destas sete empresas dos grupos americano e canadense de alto custo permitiu verificar que todas as empresas que captaram recursos a taxas próximas às taxas pagas pelas empresas brasileiras foram empresas em péssimas condições financeiras, certamente muito piores do que as das piores empresas periféricas da amostra. Com exceção da Domtar, que se recuperou a partir de 1994, todas as outras seis empresas acumularam enormes prejuízos - 3 delas chegaram a apresentar PL negativo -, enormes dívidas e cinco delas acabaram sendo vendidas para (ou fundidas com) os seus concorrentes. 


\section{CONCLUSÃO}

No item 3, foi estudado o desempenho das empresas brasileiras comparativamente às primeiras cinco empresas segundo uma série de indicadores financeiros. Os indicadores estudados foram a rentabilidade, a cobertura das despesas financeiras pelo fluxo de caixa, o custo da dívida, a alavancagem, o tamanho das empresas e o posicionamento das despesas financeiras em relação ao fluxo de caixa. Por todas estas análises e comparações, podem ser extraídas duas conclusões principais. Primeiro, todas as empresas bem classificadas (entre as 5 primeiras), segundo qualquer um destes indicadores, foram empresas que captaram recursos com um baixo custo nos mercados americano e internacional de bonds. Em segundo lugar, todas as empresas brasileiras aqui estudadas estiveram por todos os indicadores exceto uma mal classificada. As empresas brasileiras apresentaram baixa rentabilidade (PL histórico), baixos índices de cobertura, pequeno tamanho, entre outros. O único critério que mostra as empresas brasileiras bem classificadas foi a alavancagem (PL histórico), o que confirmou a baixa participação que as fontes externas tiveram, e ainda têm, no financiamento do investimento destas empresas.

No item 4, as análises específicas de cada uma das sete empresas dos grupos, americano e canadense, de "alto custo" de captação, permitiram con- firmar que realmente as empresas brasileiras não possuem qualquer semelhança com estas empresas. Da amostra, além das brasileiras, quem pagou caro nos mercados financeiros americano e internacional foram exclusivamente empresas que estavam "quebrando". Com exceção da Domtar, que se recuperou, as empresas que pagaram caro para captar recursos foram empresas que apenas não foram à falência porque algum concorrente ou alguma "investment firm" de "Wall Streef" encontrou uma solução financeira criativa em benefício próprio.

Concluindo, pode-se dizer que as empresas brasileiras não são boas, segundo os indicadores aqui analisados, como as empresas que captam recursos nos mercados financeiros com um baixo custo, mas também podemos afirmar que as empresas brasileiras também não são empresas "quebradas" como as que pagam altos custos nestes mesmos mercados. Ou seja, o mau desempenho das empresas brasileiras não justifica o alto custo de captação que têm, próximo ao de empresas em situação financeira completamente deteriorada. $O$ mau desempenho financeiro das empresas brasileiras pode explicar uma parte do custo, mas dificilmente pode explicá-lo completamente.

O segundo grande elemento, além do risco da empresa, que tem forte influência no custo de captação das empresas nos mercados financeiros internacionais é o risco dos seus países. Dada a importância desse aspecto, um próximo trabalho será dedicado a este tema. 


\section{REFERÊNCIAS BIBLIOGRÁFICAS}

ALFORD, Andrew, JONES, Jennifer, LEFTWICH, Richard, ZMIJEWSKI, Mark. The Relative Informativeness of Accounting Disclosures in Different Countries. Journal of Accounting Research, Vol. 31 supplement 1993.

BACIC, M. J. Fragilidade Financeira e Alavancagem: Uma Aplicação no Segmento das Maiores Empresas Brasileiras (1980-1987). Dissertação de Mestrado. Campinas: IE/UNICAMP, 1990.

BAUMOL, W., MALKIEL, B. Redundant Regulation of Foreign Security Trading and U.S. Competitiveness. Journal of Applied Corporate Finance 5, 1993.

BONDWARE-CAPITAL DATA. London: Capital Data Ltd, 1998-99.

CHAN, Kam C., SEOW, Gim S. The Association between Stock Returns and Foreign GAAP Earnings versus Earnings Adjusted to U.S. GAAP. Journal of Accountings and Economics 21, 1996.

CHOI, Frederick D.S., LEVICH, Richard M. Behavioral Effects of International Accounting Diversity. Accounting Horizons, jun 1991.

CSA-SEDAR SYSTEM FOR ELECTRONIC DOCUMENT ANALYSIS AND RETRIEVAL. Canada: Canadian Securities Administrators (CSA), 1998-99.

DISCLOSURE WORLDSCOPE \& SEC DATABASE. Bethesda - MD: Disclosure Incorporated, 1998-99.

ECONOMÁTICA. São Paulo: 1998-99.

EDERINGTON, Louis H., YAWITZ, Jess B., ROBERTS, Brian E. The Information Content of Bond Ratings. The Journal of Financial Research, Fall 1987.

EICHENGREEN, Barry, MODY, Ashoka. What Explains Changing Spreads on Emerging-Market Debt: Fundamentals or Market Sentiment? Working Paper Series, National Bureau of Economic Research, fev 1998.

FIPECAFI - MELHORES E MAIORES - ARQUIVO MELHORES E MAIORES REVISTA EXAME. São Paulo: Departamento de Contabilidade e Atuária - FEA/USP, 1998-99.
KAMIN, Steven B., KLEIST, Karsten von. The Evolution and Determinants of Emerging Market Credit Spreads in the 1990s. Basle - Switzerland: BIS Working Papers 68, Bank for International Settlements, May, 1999.

MEEK, G.K. U.S. Securities Market Responses to Alternative Earnings Disclosures of Non-U.S. Multinational Corporations. The Accounting Review 58, 1983.

MINSKY, H. Can it Happen Again? New York: Mc Sharpe, Inc., 1982.

MOODY'S BOND RECORD - FINANCIAL INFORMATION SERVICES. New York: Financial Communications Co, vários números.

NEW YORK TIMES - NYT. New York: vários números.

RAJAN, Raghuram G., ZINGALES, Luigi. What Do We Know about Capital Structure? Some Evidence from International Data. The Journal of Finance, dez 1995.

SEC-EDGAR ELECTRONIC DATA GATHERING, ANALYSIS, AND RETRIEVAL SYSTEM. Estados Unidos: U.S. Securities and Exchange Comission (SEC), 1998-99.

STANDARD \& POOR'S RATING DIRECT. New York: Standard \& Poor's, 1998-99.

THE WALL STREET JOURNAL - TWSJ. New York: Dow Jones \& Company Inc., vários números.

VALLE, Mauricio Ribeiro do. Eurobonds: Aspectos do Mercado e do Instrumento. Dissertação de Mestrado. São Paulo: EAESP/FGV - Fundação Getúlio Vargas, 1995.

VALLE, Mauricio Ribeiro do. O Custo de Captação nos Mercados Americano de Bonds e Internacional de Eurobonds: Uma Análise das Maiores Empresas do Setor Papel \& Celulose, Tese de Doutorado. São Paulo: Departamento de Contabilidade - FEA/USP, 2000.

ZIEBART, David A., REITER, Sara A. Bond Ratings, Bond Yields and Financial Information. Mississauga: Contemporary Accounting Research, fall 1992. 